\title{
Effect of casting practice on the reliability of Al cast alloys
}

\author{
M. A. El-Sayed ${ }^{1}$, Hany Hassanin ${ }^{2,}$ Khamis Essa ${ }^{3}$ \\ ${ }^{1}$ Department of Industrial and Management Engineering, Arab Academy for Science and Technology and Maritime Transport, Abu Qir, PO Box \\ 1029, Alexandria 21599, Egypt. Email m elsayed@aast.edu \\ ${ }^{2}$ School of Mechanical and Automotive Engineering, Kingston University, London, UK. Email h.hassanin@kingston.ac.uk \\ ${ }^{3}$ School of Mechanical Engineering, University of Birmingham, Birmingham, UK. Email k.e.a.essa@bham.ac.uk
}

\begin{abstract}
The properties of aluminium castings are strongly affected by their inclusion content, particularly entrained surface alumina films. These form due to the surface turbulence associated with mould filling, which causes the oxidised surface of a liquid metal to fold-over onto itself and be submerged into the bulk liquid with a thin layer of air entrapped within it. This is known as entrainment action. These flaws have been reported to increase the variability of the fracture strengths of $\mathrm{Al}$ alloy castings. This means that shape castings in light alloys can have inconsistent properties, which makes designing structures employing shape castings more difficult. Entrained surface layers can cause premature failure, but also have been associated with other defects, such as hydrogen porosity, shrinkage porosity, intermetallic compounds and hot tearing. Recent research has suggested that the air inside the defect would react with the surrounding melt leading to its consumption, which may enhance the mechanical properties of the casting. In this work, liquid aluminium was poured into three identical ceramic moulds which were immediately placed in a furnace to preserve the molten metal at $800 \mathrm{C}$, for different periods of time prior to freezing. The Weibull moduli of the plate castings were determined under tensile conditions, and their fracture surfaces examined using SEM. Investigation of the fracture surfaces of the specimens detected many alumina layers at different locations. Many of which were found inside pores, reflecting the role of entrained defects in the formation of porosity. The results also suggested that opposite phenomena may take place during the holding treatment. The consumption of air inside the entrained defects due to reaction with the surrounding molten metal may lead to improvements in mechanical properties, but this may be accompanied by hydrogen passing into the defects, which has a deleterious effect on properties.
\end{abstract}

Keywords: entrained inclusions, aluminium casting, porosity, mechanical properties.

\section{Introduction}

In response to consumer demands for increased performance and fuel economy, the use of aluminium in the automotive and aerospace industries has grown dramatically in recent years. Today, significant amounts of cast aluminium alloys are being used to fabricate components such as engine blocks, cylinder heads, wheels, and pistons.

As the use of cast aluminium has increased, so have the mechanical property requirements, and since the mechanical properties of the $\mathrm{Al}$ castings are greatly affected by their inclusion 
contents; it is important to study these inclusions, their types, causes and harmful influences on castings. One of the most significant inclusions is the entrained surface film defect, or a bifilm, which has been reported by many researchers to have detrimental effects on the reliability and reproducibility of $\mathrm{Al}$ castings [1].

During the casting of aluminium alloys, the melt surface is exposed to air which results in the formation of a surface oxide film. As a result of the surface turbulence, which is a common feature during metal transfer and pouring in the casting process, the surface of the liquid metal is folded over itself. This causes the upper and lower oxidised surfaces of the foldedover metal to come together and trap a layer of the mould atmosphere between them, creating a bifilm defect. This defect is then incorporated into the bulk liquid in an entrainment action $[1,2]$, as shown in Figure 1.

(1)

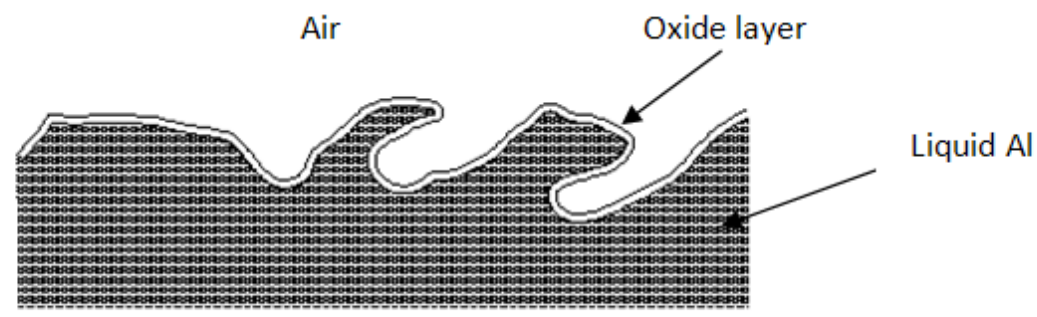

(2)

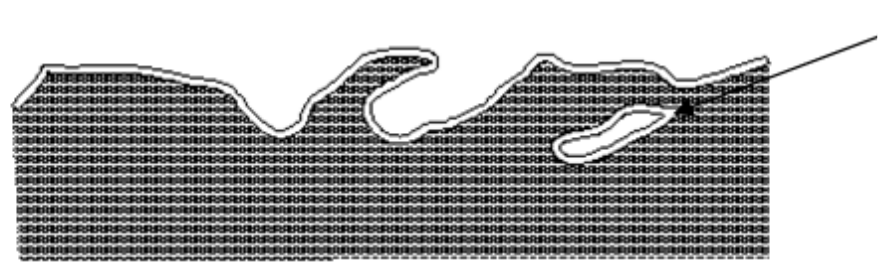

Bifilm defect

Figure 1. The formation of a bifilm defect (1) surface turbulence leads to a breaking wave on the metal surface, and (2) the two unwetted sides of the oxide layer contact each other leading to the submerging of the bifilm into the bulk liquid metal.

A bifilm defect consists of two oxidised surfaces, (typically Al2O3, MgAl2O4 or MgO, depending on alloy composition), with an air layer entrapped between them. This class of defects is almost two-dimensional. They may have an area measured in square millimetres, but be only a few microns thick and are therefore undetectable by conventional means.

Entrained bifilm defects represent the easiest possible initiating features for cracks, decohesion or pore, since they are not in atomic contact with the liquid and their unbounded dry inner surfaces could be separated with minimal effort. In a study for the fatigue properties of Al-7Si-0.4Mg alloy castings, Nyahumwa et al.[3], reported that in about $98 \%$ of all fatigue fractures, bifilms were the initiators of cracks. The remaining $2 \%$ that did not contain bifilms exhibited up to 100 times greater fatigue lives.

Campbell [2], clarified the role played by bifilms as follows; after entrainment and due to the internal turbulence in the bulk liquid, the entrained film is compacted in a convoluted form. 
Afterwards, the bifilm would unfurl in the quiescent conditions of the mould cavity and then re-establish its shape as a planer crack. Moreover; during solidification, the solubility of hydrogen in the aluminium decreases significantly, and it may diffuse into the bifilm gap causing its expansion into a pore. It has also been shown that double oxide films could be favourable sites for the nucleation and growth of a wide variety of intermetallics [4].

The harmful influences of bifilms, either acting as cracks or helping in the nucleation of porosity or intermetallics can be detrimental for mechanical properties of Al castings. These consequences not only reduce the elongation, tensile strength and fatigue limit of the aluminium casting, but also increase their variability. The main objective for study of the oxide film defects was to eliminate them or at least reduce their deteriorous effects on the properties of aluminium melts.

Nyahumwa et al. [5] suggested that, due to the transformation of the oxide layer from $\gamma$ $\mathrm{Al}_{2} \mathrm{O}_{3}$ to $\alpha-\mathrm{Al}_{2} \mathrm{O}_{3}$, ( a process thought to take about 5 hours), cracks are introduced into the oxide skin which allows the liquid aluminium to come into contact with, and react with, the atmosphere inside the defect (mainly oxygen and nitrogen). This mechanism could result in the consumption of the atmosphere inside the bifilm and possibly lead to its deactivation.

This explanation was further supported by Griffiths and Raiszadeh who trapped an air bubble (as a proxy for a bifilm) inside liquid $\mathrm{Al}$ and monitored its change in volume with time using real-time $x$-ray radiography. Their results showed that the oxygen in the trapped air should be consumed first, to form $\mathrm{Al}_{2} \mathrm{O}_{3}$, then the nitrogen would react to form AlN. These reactions started immediately, (with no need for an initiating phase transformation). They also reported an increase in the volume of the bubble when the initial hydrogen content of the melt was higher than the equilibrium associated with the ambient atmosphere, which was suggested to be due to hydrogen diffusion into the bubble [6].

A more detailed experiment, using a Pore Gas Analyser to investigate the change in the composition of an air bubble trapped in different $\mathrm{Al}$ alloys [7, 8], has demonstrated that hydrogen can diffuse through an oxide layer showing how a double oxide film defect can grow into a hydrogen-filled pore.

The aim of the work reported here was to study the effect of time on the shape of the entrained bifilm defects, and hence on the mechanical properties of the resulting castings. The main objective of this study of bifilms was to learn if they could be eliminated or at least if their deleterious effects could be reduced.

\section{Experimental Work}

The experimental work involved carrying out three experiments to produce castings from $1100 \mathrm{Al}$ alloy that containing bifilms of different lifetimes; 0, 10 and 20 minutes. Chemical composition of alloy is given in Table 1 . In each experiment about $10 \mathrm{~kg}$ of the aluminium were melted in an induction furnace. Once the temperature of the melt reached $850^{\circ} \mathrm{C}$, the crucible containing the liquid metal was placed in a vacuum chamber, where the melt was 
held at about $800^{\circ} \mathrm{C}$, under a vacuum of about 0.2 bar for two hours, a procedure intended to remove previously introduced bifilms from the melt [9].

Table 1. Chemical composition of $1100 \mathrm{Al}$ alloy

\begin{tabular}{|c|c|c|c|c|c|}
\hline Element & $\mathrm{Si}$ & $\mathrm{Fe}$ & $\mathrm{Cu}$ & $\mathrm{Cr}$ & $\mathrm{Al}$ \\
\hline$\%$ & 0.3 & 0.6 & 0.15 & 0.1 & $\mathrm{Bal}$. \\
\hline
\end{tabular}

The liquid metal was then prepared in such a way as to promote surface turbulence and splashing, by being poured from a height into preheated ceramic shell moulds, and being stirred in an induction furnace, (using a power setting of $7.5 \mathrm{~kW}$ and frequency of $2350 \mathrm{~Hz}$, for one minute). This was intended to cause the creation and entrainment of new bifilm defects, and their introduction into the melt.

In one experiment the casting was allowed to solidify immediately to preserve any bifilm defects created during the melt stirring or mould filling. In the other two experiments it was maintained in the liquid state by placing the filled ceramic shell mould in a resistance-heated furnace for 10 and 20 minutes, before removing it to allow solidification. Thus any bifilms generated in these cases were known to be about 10 and 20 minutes old respectively. During holding of the melt, the hydrogen content was evaluated.

After solidification, each of the castings was machined into 20 tensile test bars, for determination of their Ultimate Tensile Strength and \%Elongation at failure, using a crosshead velocity of $1 \mathrm{~mm} \mathrm{~min}^{-1}$. The tensile results were evaluated using a Weibull statistical analysis approach to assess the influence of the holding period on the variability of the mechanical properties of the castings. Finally, the fracture surfaces of the test bars were examined using an SEM.

\section{Results}

The two-parameter Weibull distribution was used to analyse the scatter in the mechanical properties of the $1100 \mathrm{Al}$ alloy castings that were kept melted for different periods before solidification, because it was more appropriate than a normal fit [10]. The Weibull modulus (the slope of the line fitted to the log-log Weibull cumulative distribution data) is a single value that shows the spread of properties; a higher Weibull modulus is indicative of a narrower spread of properties.

Figures 2 (a) and (b) show Weibull plots of the UTS and \% elongation, respectively, of the test bars cut from castings that were held in the furnace for 0, 10 and 20 minutes before solidification.

It was noted that for both the UTS and \% elongation, the Weibull moduli (the slope of the trend line) of the castings maintained at $800^{\circ} \mathrm{C}$ for 10 minutes prior to cooling were higher than those solidified immediately or held in the liquid state for 20 minutes before solidification. 
For each of the three alloys, the position parameter, (the characteristic stress at which 1/e of the samples survived) of both the UTS and \% elongation was quite close, which might be an indication that the holding treatment mainly affecting the scatter of the properties rather than their scale parameter.

Figure 3 (a) shows plots of the Weibull moduli of the UTS and \% Elongation of the Al alloys versus the holding time before solidification. It was shown that the Weibull modulus of the UTS increased from 14.4 (solidified immediately) to 20.9 (obtained by holding in the liquid state for 10 minutes before solidification). However, as the holding period increased to 20 minutes, the Weibull modulus was decreased to 13.3. Also, holding in the liquid state for 10 minutes raised the Weibull modulus of the percentage elongation from 8.4 to 14.7, but the modulus was subsequently reduced to 6.6 when the holding period was increased to 20 minutes. Figure 3 (b) shows a plot of the amount of hydrogen in solution in the liquid metal against holding time, the hydrogen content of the alloy consistently increased with holding time.

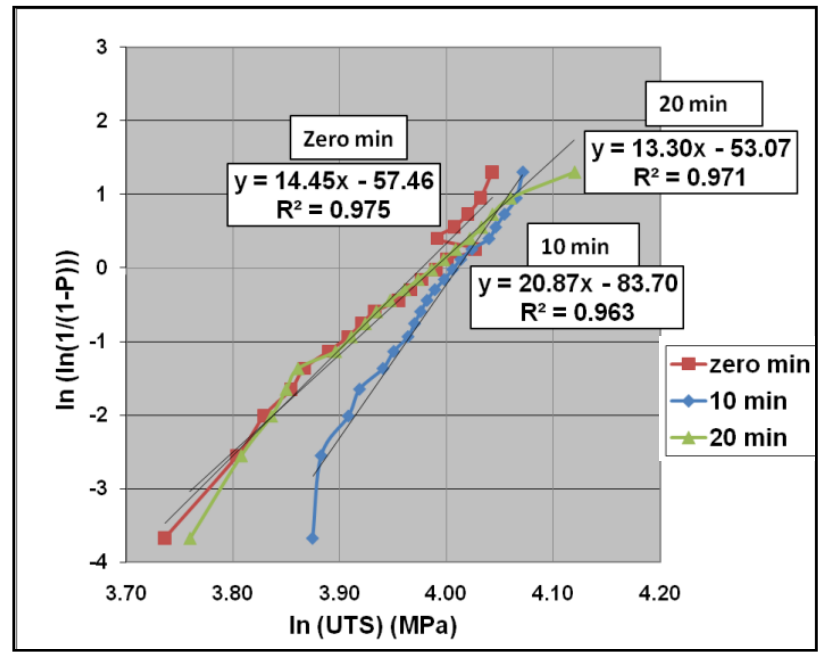

(a)

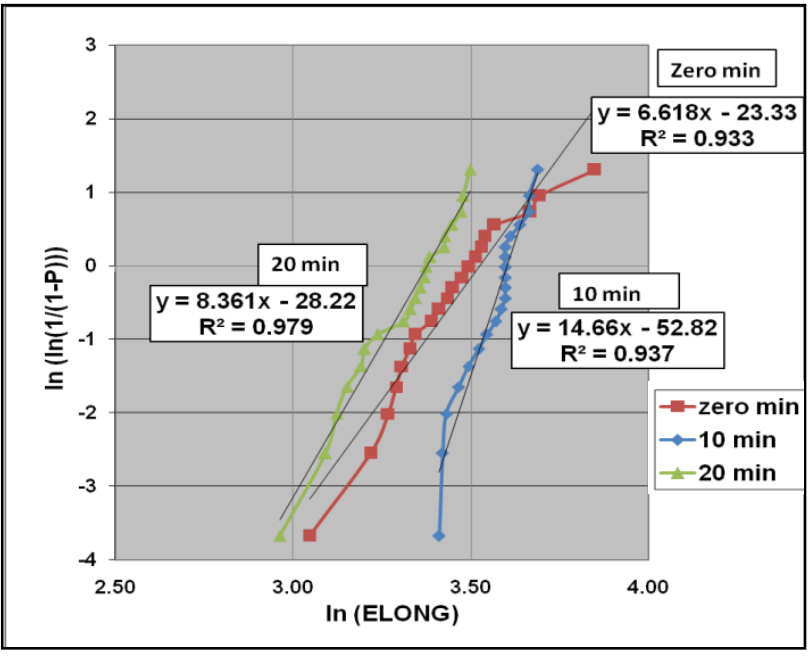

(b)

Figure 2. Weibull distribution of (a) the ultimate tensile strength and (b) the \% elongation of $1100 \mathrm{Al}$ alloy specimens held in the liquid state for 0,10 and $20 \mathrm{~min}$. before solidification.

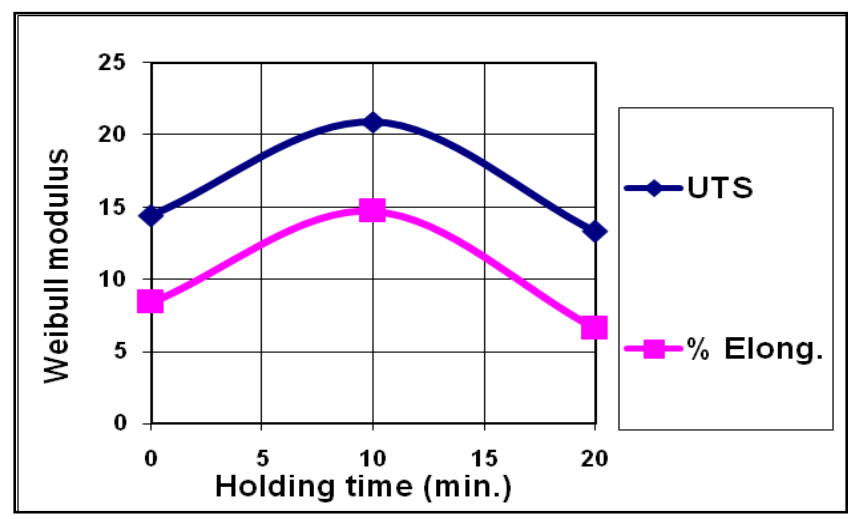

(a)

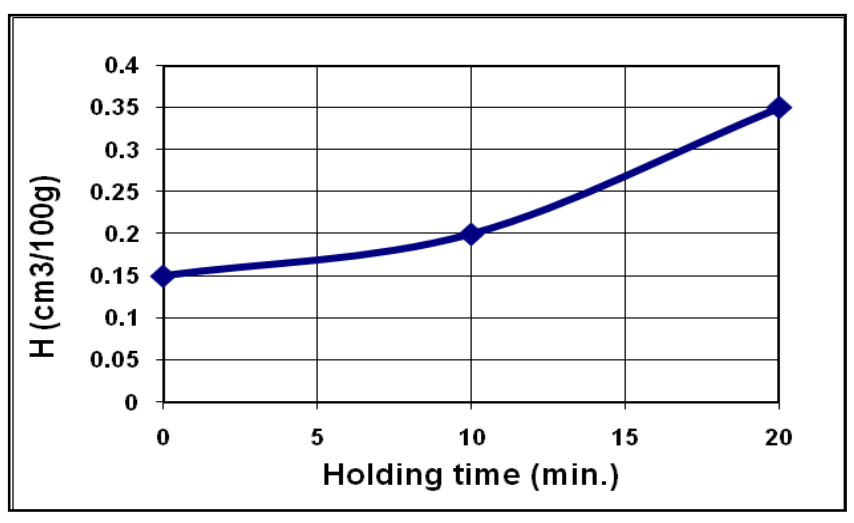

(b)

Figure 3. Plots of holding time versus (a) Weibull Modulus of the UTS and \% Elongation, (b)

$\mathrm{H}$ content of the melt. 
Figures 4 (a) and (b) show SEM images, with the corresponding EDX analyses, for different oxide layers found on the fracture surfaces of specimens from the $\mathrm{Al}$ casting that was solidified immediately after pouring. The identity of the alumina film was confirmed by the EDX spectra accompanied with each image, in which oxygen signals were detected at the suspected bifilm layers.

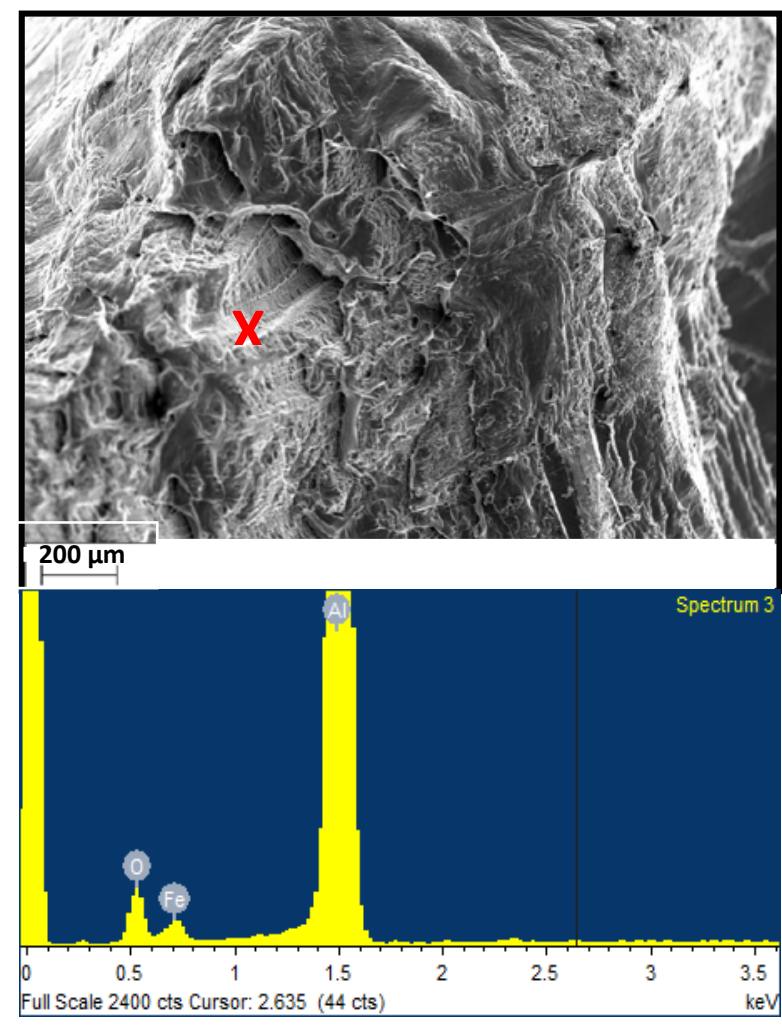

(a)

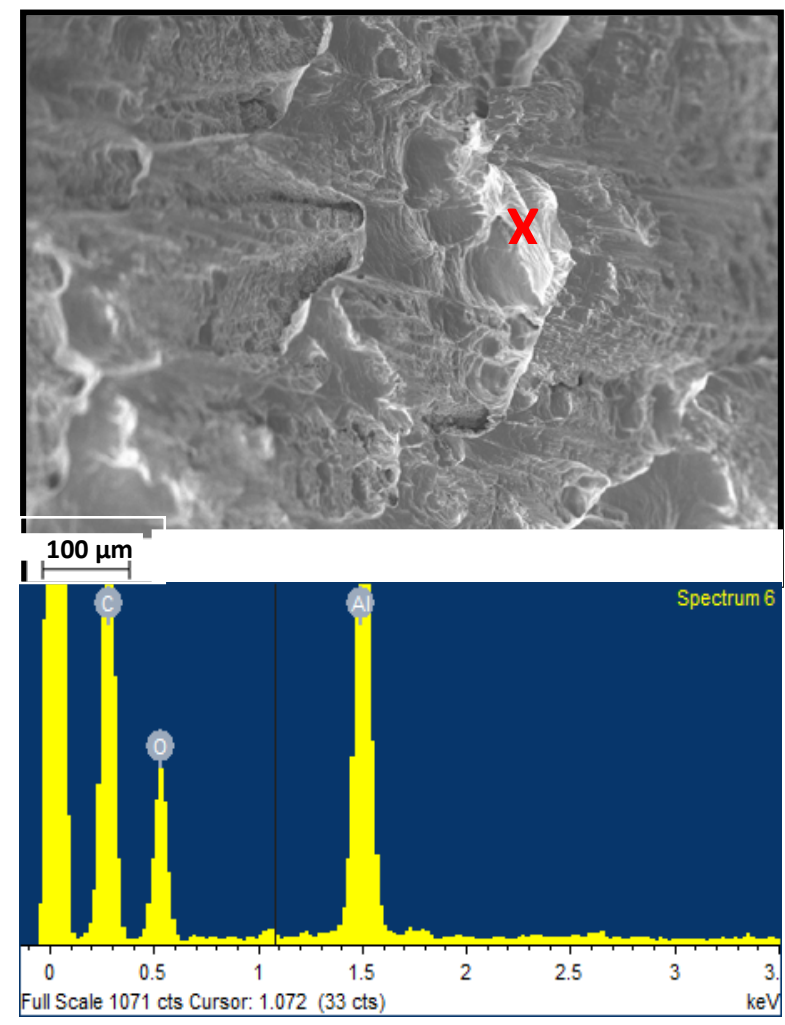

(b)

Figure 4. SEM images with corresponding EDX analysis of the fracture surfaces of $1100 \mathrm{Al}$ alloy specimens that contain zero-min. old bifilms.

It was noted that almost all of the alumina films found on the fracture surfaces (not inside the pores) of the test bars were associated with castings that had been solidified immediately after pouring. No other bifilms were found on the fracture surfaces of the test bars from other castings held in the liquid state for 10 or 20 minutes prior to cooling. This might suggest a role of the holding treatment in eliminating bifilms in $\mathrm{Al}$ castings, or at least altering their morphology.

Figures 5 (a) and (b) show SEM images inside pores on the fracture surfaces of specimens from castings with 10 and 20 minutes holding periods, respectively. Many oxide fragments were visible inside the pores, and EDX analysis of the fragments indicated the presence of $\mathrm{Al}_{2} \mathrm{O}_{3}$, suggesting that the origins of the pores were primarily bifilm defects that might have been changed their morphologies during the holding treatment to form pores. This would be an indication of the role played by bifilms in initiating porosity in light metal alloy castings. 


\section{Discussion}

The Weibull distribution plots of the UTS and the \% elongation (shown in Figures 2 and 3), showed that the Weibull moduli representing both the UTS and percentage elongation, of different $\mathrm{Al}$ alloys, experienced a peak when the castings were kept in the liquid state for 10 minutes before solidification. The moduli dropped significantly when increasing the holding period to 20 minutes. Also the hydrogen content of the $\mathrm{Al}$ melt was found to increase with the holding time, as shown in Figure 3.

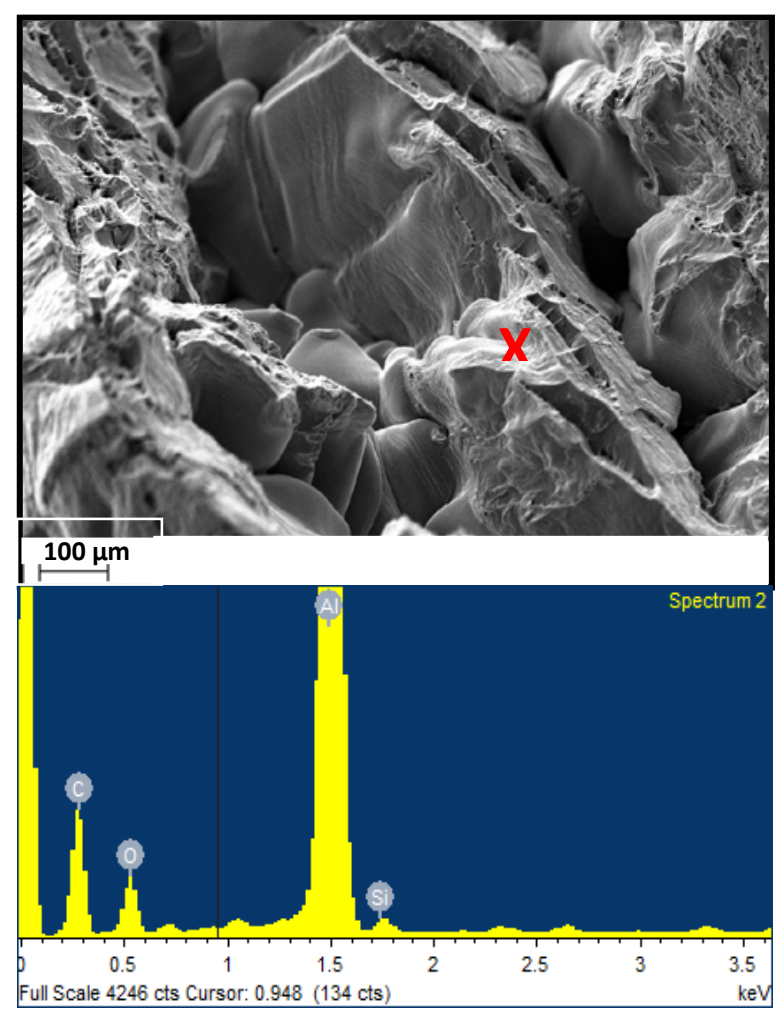

(a)

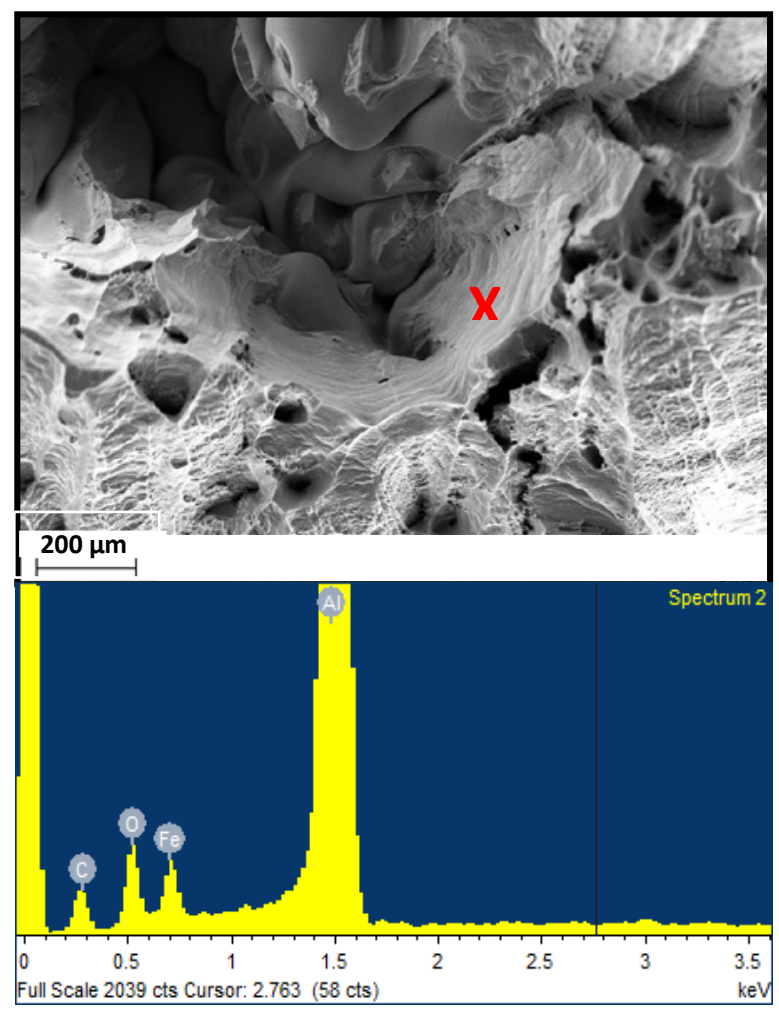

(b)

Figure 5. SEM images with corresponding EDX analysis of the fracture surfaces of $1100 \mathrm{Al}$ alloy specimens illutrating pores containing oxide films of different ages, (a) 10 min. and (b) $20 \mathrm{~min}$.

In earlier studies by Raiszadeh and Griffiths [11] and El-Sayed et al. [7, 8], it was suggested that the interior atmosphere inside a bifilm could be consumed within a few minutes due to reaction with the surrounding liquid Al. This would reduce the size of bifilm defects and hence reduce their deteriorous effects on the mechanical properties of $\mathrm{Al}$ castings.

The peak in Weibull moduli at 10 minutes suggests that two gainsaying situations were taking place simultaneously during the holding of an $\mathrm{Al}$ casting in the liquid state prior to solidification. The first situation was related to the reaction between oxygen and nitrogen within the bifilm defect with the contiguous melt which decreased their size and in turn enhance the mechanical properties of the casting. On the other hand, another action occurs which may be related to the amount of hydrogen picked up by the liquid metal from the furnace atmosphere that increased as the liquid metal was held in the furnace for longer 
periods, and this would lead to a decrease in overall mechanical properties due to increased porosity.

The Weibull moduli of the castings allowed to solidify immediately after pouring signified the variability of tensile properties of castings with bifilms that were beginning to lose their internal atmosphere, but also had the lowest $\mathrm{H}$ levels.

During the early stages of holding the first phenomenon, consumption of air inside the bifilms, was more dominant, and there was a noticeable enhancement in the Weibull moduli of both UTS and \% elongation, which reached a maximum at 10 minutes. It could be suggested that, at this time, bifilm defects may have lost most of their $\mathrm{O}$ and $\mathrm{N}$ by reaction with the surrounding liquid $\mathrm{Al}$, while allowing only a small increase in $\mathrm{H}$ content. Consequently, the shape of the bifilms would be expected to be less deteriorous to the mechanical properties of the castings.

However, increasing the holding time to 20 minutes did not cause any further improvement in the mechanical properties as most of the initial atmosphere of bifilms had already been consumed. On the contrary, the extended holding resulted in a decline in the Weibull moduli due to an increasing $\mathrm{H}$ content of the melt and hence an increasing $\mathrm{H}$ content of the defect and of the porosity size in the final casting.

The SEM investigation of the fracture surfaces of specimens with different holding periods detected few alumina films lying on the surface, shown in Figure 4. Almost all of them were from castings solidified immediately after pouring. However, alumina films, as demonstrated by EDX analysis in the SEM, were mostly associated with pores, (as shown in Figure 5, rather than lying on the fracture surfaces. This could be an indication of the effect of the holding treatment on the deactivation of oxide films.

It was suggested by Griffiths and Raiszadeh [6], that hydrogen dissolved in the Al melt could diffuse into the bifilm causing its expansion into a pore, which might be subsequently torn apart (due to their extremely thinness) leaving only some oxide fragments inside the pores. Therefore, it could be speculated that these oxide-related pores may have been formed due to the diffusion of $\mathrm{H}$ from the melt into bifilms. This could be in accordance with the results of the Weibull modulus analysis that suggested a role for the diffused hydrogen into the bifilms in increasing the size of the defects and hence worsen the mechanical properties of the castings.

To summarise, the change in mechanical properties suggest that bifilm defects, once formed, quickly undergo changes in their internal atmosphere which influence their effect on mechanical properties by influencing their size and shape. These changes are the consumption of oxygen and nitrogen in the bifilm atmosphere which reduce the size of the defects and then improves the properties, and the diffusion of hydrogen in the bifilms, increasing their size and making the properties worse. 


\section{Conclusions}

1- SEM examination of the fracture surfaces revealed the presence of oxide films, most of them were associated with pores, which demonstrated a role for such defects in influencing the failure of $\mathrm{Al}$ castings.

2- Holding Al castings in the liquid state for up to 20 minutes before solidification resulted in peak values of the Weibull Modulus occurring at a nominal holding period of 10 minutes.

3- Bifilm defects in liquid Al alloys may have variable effects on casting properties, depending on their morphology (mainly size and shape). This morphology can be influenced by reaction their interior atmospheres with the surrounding melt, and diffusion of hydrogen into the defect. This could cause a planer crack to expand forming a pore.

4- The holding treatment may reduce the effect of double oxide film defects in $\mathrm{Al}$ melts, but would not prevent them from serving as sites for the formation of hydrogen porosity in $\mathrm{Al}$ castings.

\section{References}

1. J. Campbell, Castings, second ed., 2003, Butterworth-Heinemann, London.

2. J. Campbell. Mater. Sci. Technol., 2006, 22, 127-145.

3. C. Nyahumwa, N.R. Green, and J. Campbell, Mech. Beh. M., 1998, 9, 227-235.

4. X. Cao, and J. Campbell, Metall. Mater. Trans. A, 2003, 34, 1409-1420.

5. C. Nyahumwa, N.R. Green, and J. Campbell, AFS Trans., 1998, 106, 215-223.

6. W.D. Griffiths and R. Raiszadeh, J. Mater. Sci., 2009, 44, 3402-3407.

7. M. El-Sayed, H. Salem, A. Kandeil, and W.D. Griffiths, Mater. Sci. Forum., 2013, 765, 260-265.

8. M. El-Sayed, H. Salem, A. Kandeil, and W.D. Griffiths, Metall. Mater. Trans. B, 2014, 45, 1398-1406.

9. R. Raiszadeh and W.D. Griffiths, J. Alloy Compd, 2010, 491, 575-580.

10. N.R. Green and J. Campbell, Mat. Sci. Eng. A, 1993, 173, 261-266.

11. R. Raiszadeh and W.D. Griffiths, Met. Trans., 2006, 37B, 865-871. 